\title{
3D sketching of the fortified entrance of the Citadel of Aleppo from a few sightseeing photos
}

\author{
Jean-Baptiste Barreau ${ }^{1}$, Emmanuel Lanoë ${ }^{1}$, Ronan Gaugne ${ }^{2}$ \\ ${ }^{1}$ Univ Rennes, CNRS, Ministère de la culture et de la communication, INRAP \\ CReAAH - UMR 6566, \\ F-35000 Rennes, France \\ jean-baptiste.barreau@univ-rennes1.fr, emmanuel.lanoe@inrap.fr \\ ${ }^{2}$ Univ Rennes, Inria, CNRS, IRISA \\ Rennes, France \\ ronan.gaugne@irisa.fr
}

\begin{abstract}
Originally built during the Ayyubid era by the son of Saladin, al-Malik al-Zahir Ghazi (11861216), and rebuilt throughout the Mamluk era (1260-1516), the entrance to the citadel of Aleppo was particularly affected by an earthquake in 1822, bombings during the Battle of Aleppo in August 2012, and a collapse of ramparts due to an explosion in July 2015. Even if compared to other Syrian sites, there are still enough vestiges to grasp the initial architecture, the civil war situation makes extremely difficult any "classic" process of digitization by photogrammetry or laser scanning. On this basis, we propose a process to produce a 3D model "as relevant as possible" only from a few sightseeing photographs. This process combines fast 3D sketching by photogrammetry, 3D modeling, texture mapping and relies on a corpus based on pictures available on the net. Furthermore, it has the advantage to be applicable to destroyed monuments if sufficient pictures are available. Five photos taken in 2005 by a tourist archaeologist around the entrance were first used to generate a partial and poor quality point cloud with photogrammetry. The main elements of the inner gate and a part of the arched bridge are distinguishable on the point. Because the architecture is fairly rectilinear and symmetrical, it has been possible to redraw in 3D most of the outlines by constantly comparing with what is visible on these first photos. The next step is the enrichment of the 3D model from the initial geometric basis and thanks to a corpus of photos available on the internet. This corpus was constituted from selection of pictures obtained with a search on Google Web Search and the keywords "Citadel" and "Aleppo". The selection took into account both the resolution of the images and the coverage of the items of interest and gathered 66 pictures. The enrichment of the 3D model is performed through an iterative process made up of four main steps: (i) orthophoto extraction from some photos of the corpus (ii) 3D modeling from these orthophotos (iii) seamless texture extraction (iv) texture mapping. There are still some uncovered lateral areas, unreadable engraved wall writings, and some details are reconstructed naively, but the essential items, allowing to visually characterize the fortified entrance as a whole, have been reconstituted. The 3D model was first used to produce some renderings intended to obtain first reviews from archaeologists and architecture specialists, photos and complementary documents allowing correcting and filling the gaps. We wish to set a collaborative process to improve the model, based on an exchange with experts of the domain. The resulting model aims at feeding an interactive website dedicated to 3D display of heritage under threats. Other rendering of the model such as virtual reality or 3D printing could also be considered to share this testimony of our heritage. The application of this methodology to other sites deserves further studies that would depend on the possibilities of photogrammetry, the architectural complexities and human means for 3D modeling.
\end{abstract}

Keywords. Crowd-sourced photogrammetry, 3D sketching, endangered heritage, Syrian Cultural Heritage

\section{Introduction}

Aleppo is the second city in Syria. It has a really important architectural heritage and is in the UNESCO World Heritage List. Islamic ruling made it a great city by re-built walls, gates, towers and the citadel. Recently, this heritage have been destroyed due to the internal war in Syria [3]. Previously, Aleppo was also destroyed several times when Hulagu Khan placed it under siege in 1260 [12] and in 1822 with an 
earthquake [19] which demolished 30\% of its building (cf. Figure 1). The conservation, transformation, destruction, and re-invention of the heritage has been thus well-studied [20]. Originally built during the Ayyubid era by the son of Saladin, al-Malik al-Zahir Ghazi (1186-1216), and rebuilt throughout the Mamluk era (1260-1516) until Al-Achraf Qânsûh Al-Ghûrî, the entrance to the citadel of Aleppo was particularly affected by the earthquake, bombings during the Battle of Aleppo in August 2012, and a collapse of ramparts due to an explosion in July 2015 (cf. Figure 2).
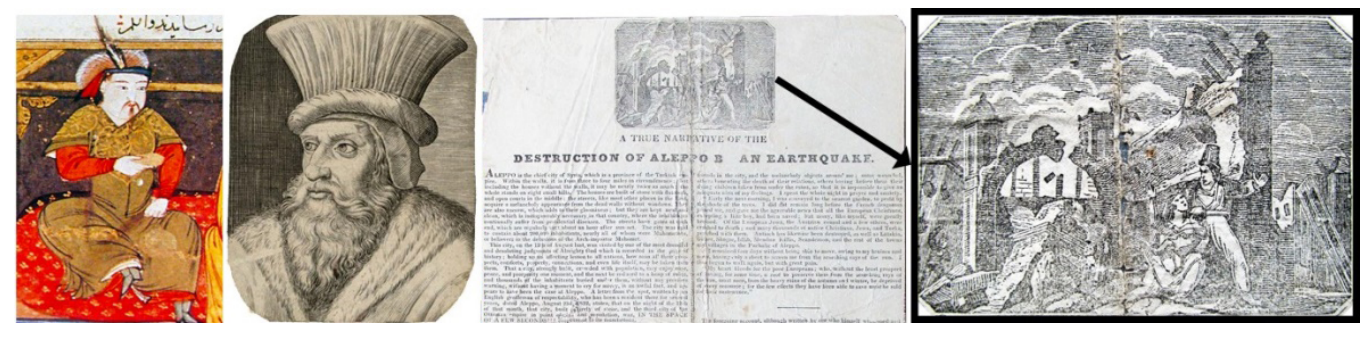

Fig. 1. Painting of Hulagu Khan (by Rashid-al-Din Hamadani), drawing of Al-Achraf Qânsûh Al-Ghûrî and antique newspaper broad sheet for 1822 being a narrative of the disastrous earthquake in Aleppo (sold by "Bibelots London" shop)
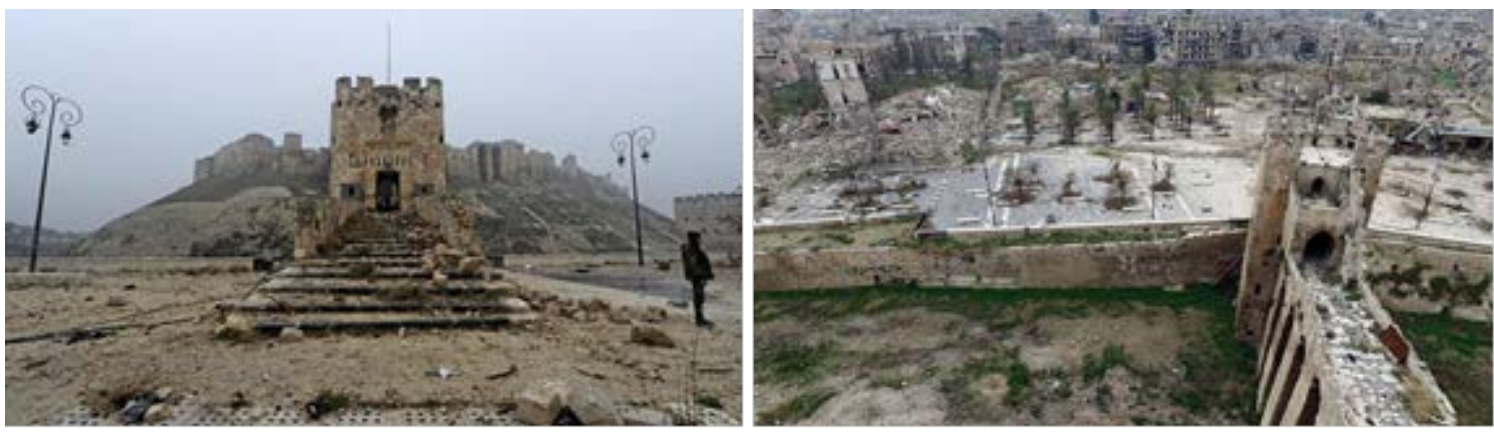

Fig. 2. In front of the citadel on 13 December 2016 (@ RFI) and urban structure around in January 2016 ( (C) Directorate-General for Antiquities and Museums)

Considering the recent events, the experiments of 3D digitizations and reconstructions of the Syrian architectural heritage are numerous. Several sites were digitally documented and reconstructed thanks to a photographic coverage of some UNESCO sites before the war through different projects, with various techniques such as spherical photogrammetry [10] [9], photogrammetry and laser scan [4]. After the beginning of war, several projects explored crowd-sourced methods to document and reconstruct the damaged or destroyed heritage. The ancient city of Palmyra was first digitized by photogrammetry thanks to a combination of professional pictures and some from the public domain [29], and the Project Mosul [28] with 3D reconstructions based on various sources of pictures.

In the case of the Citadel of Aleppo, different existing works of 3D representation. With his photomodelling, W. Wabeh allows a global visualization of the building from a point of view located on the adjoining street [9]. We can also cite a 3D model of the Citadel in sketchfab [16], and 3D elements of gameplay in video game environments, such as Minecraft and Uncharted [8] (cf. Figure 3). 


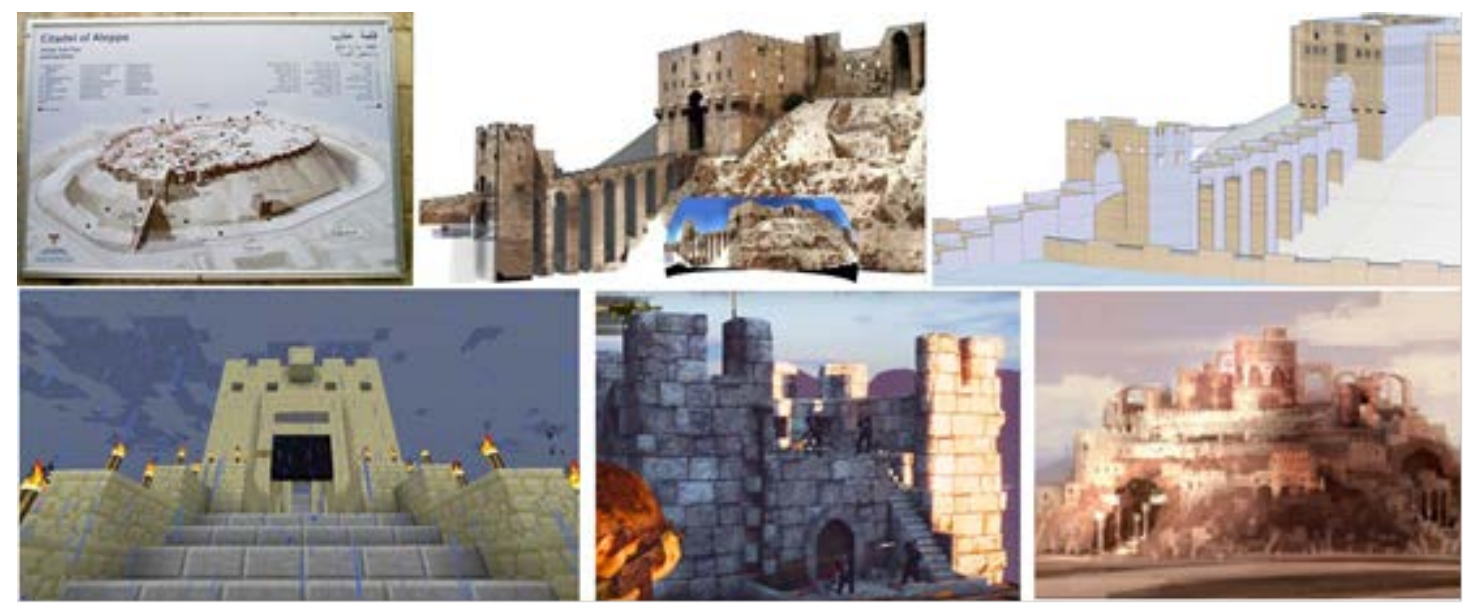

Fig. 3. Top: 3d models from a visitor site plan [1], CIPA database [9], Sketchfab [16] / Bottom: the video games Minecraft [2] (left) and Uncharted 3 (center and right) [8]

Currently and even if compared to other Syrian sites, there are still enough vestiges to grasp the initial architecture, the geopolitical situation makes extremely difficult any "classic" process of digitization by photogrammetry or laser scanning. In parallel with this, at the same time, the close-range photogrammetry has been used for at least a decade to reconstruct buildings as they were before their destruction [31]. In the reference book dedicated to it [22], it is defined that the close-range photogrammetry "encompasses methods of image measurement and interpretation in order to derive the shape and location of an object from one or more photographs of that object". With the advent of crowdsourcing, participatory photogrammetry strategies emerge [15], especially from heterogeneous sources [14] [24]. The iconographic databases concerning heritage, for research and teaching purposes, are also widely used today [21] [26].

This paper proposes a process to produce a 3D representation of the entrance to the citadel of Aleppo, as it was before destruction and enough detailed for a close point of view, from a very poor photographic coverage of the monument. This production took place as part of the West Digital Conservatory of Archaeological Heritage project [5].

\section{Method}

Our approach focuses on the fact that we have fixed constraints concerning the corpus of photos at our disposal, in order to test the possibility of doing the best with a minimum of resources. Examples of 3D productions made from very few photos, and usable in the context of scientific reasoning, are scarcely available. Among them, we can point a relatively old work of control survey of a drilling platform (16 photos) [6] and, more recently, 2 studies of collision crush [13] and forensic 3D analysis [23] (sometimes only 2 - 3 photos).

Our global process, based on the work of Kitamoto et al [18], can be described in 5 steps (cf. Figure 4):

1. Selection of sightseeing photos taken with the same camera, zoom and lighting settings

2. Photogrammetry and mesh generation

3. Manual modeling of volumes from the photogrammetry mesh and symmetric deductions

4. Selection of a corpus of photos available on the internet showing the details of the characteristic elements of the building

5. Texture mapping and renderings 


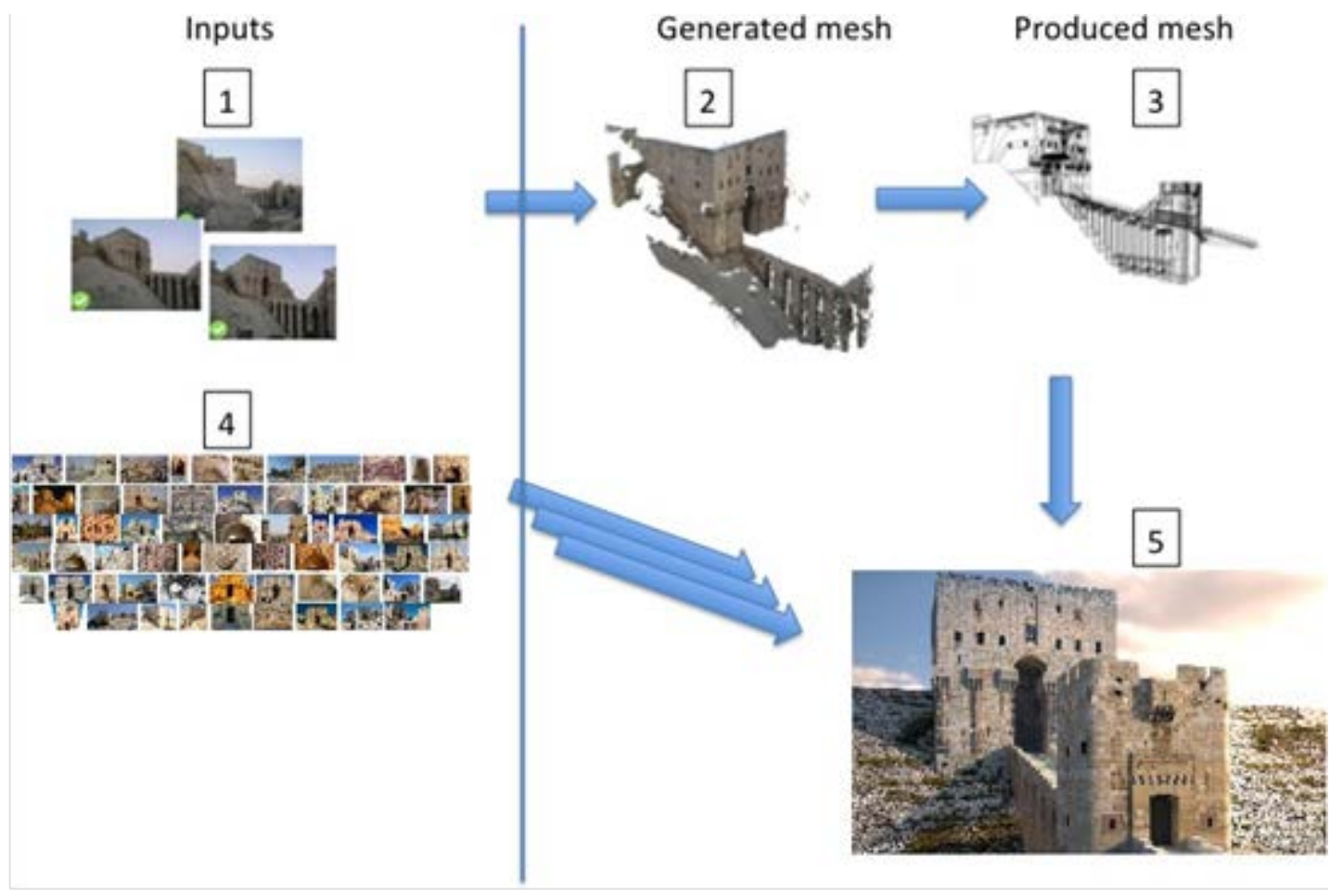

Fig. 4. Presentation of the global process

\subsection{Modeling of volumes}

Thus, five photos taken in 2005 by a tourist archaeologist around the entrance were first selected and used to generate a partial and poor quality cloud with photogrammetry. It was done with Agisoft Photoscan Professionnal Edition 1.2.2 and the numerical results are summarized in the table 1. The main elements of the inner gate and a part of the arched bridge are distinguished on the point (cf. Figure 5).

Table 1. Photogrammetry numerical results

\begin{tabular}{|c|c|c|c|c|c|}
\hline \multicolumn{2}{|c|}{ Photo alignment } & \multicolumn{2}{|c|}{ Dense cloud } & \multicolumn{2}{|c|}{ Mesh building } \\
\hline Accuracy & Highest & \multirow{2}{*}{ Quality } & \multirow{2}{*}{ Ultra high } & Surface type & Arbitrary \\
\hline Pair selection & Generic & & & \multirow{2}{*}{ Source data } & \multirow{2}{*}{ Dense cloud } \\
\hline Key point limit & 40000 & \multirow{2}{*}{ Depth filtering } & \multirow{2}{*}{ Aggressive } & & \\
\hline Tie point limit & 4000 & & & Intel & Extrapolated \\
\hline Camera aligned & $3 / 5$ & \multirow{2}{*}{ Points number } & \multirow{2}{*}{1131556} & \multirow{2}{*}{ Face count } & \multirow{2}{*}{226309} \\
\hline Tie points & 2034 & & & & \\
\hline
\end{tabular}




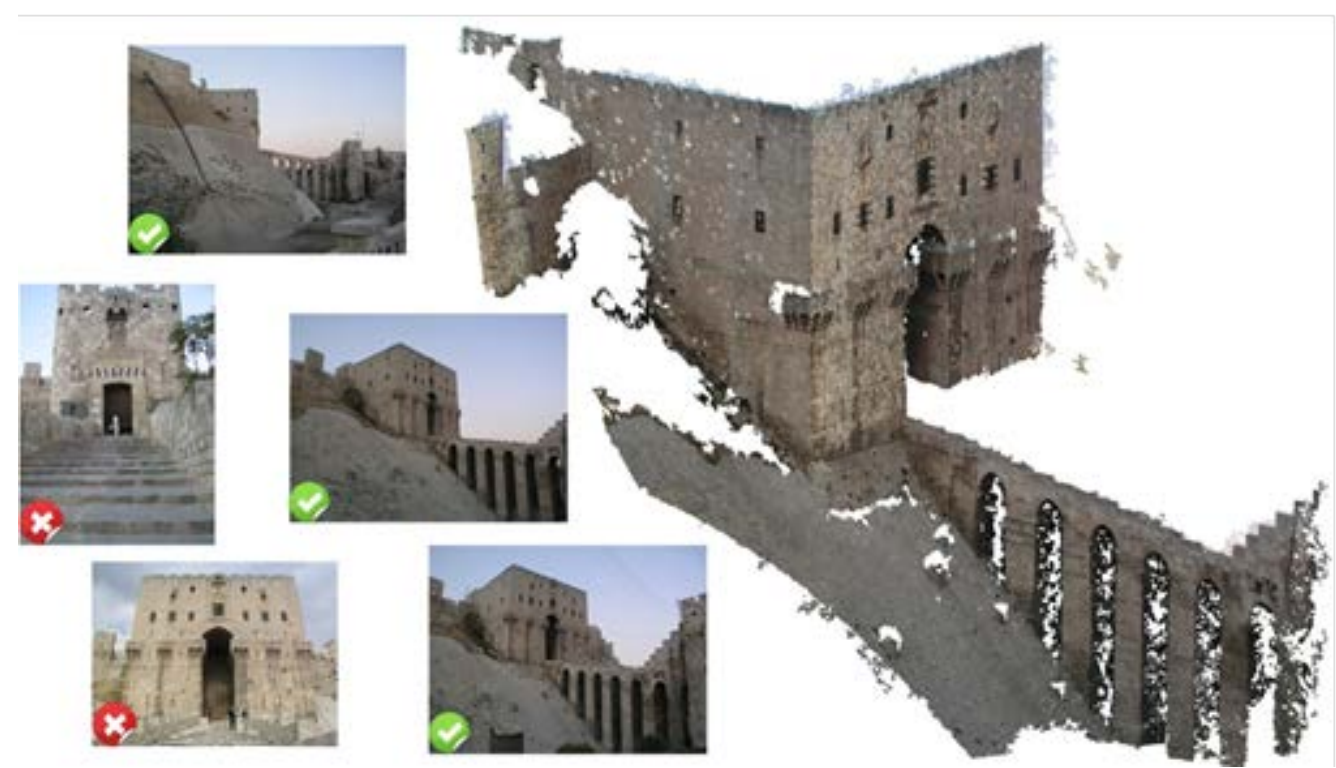

Fig. 5. Photos used to do the photogrammetry (green ticks: aligned photos / red crosses: not aligned photos) and low quality point cloud

The mesh generated by Photoscan was then integrated into the 3ds Max 2015 modeling software. There was indeed support for drawing the outlines of the main parts of the building: inner an outer gates, machicolations, entrance with reliefs depicting dragons, arched bridge and portions of ramparts around.

Because some fine details are not very noticeable on the mesh from photogrammetry, we generated orthoimages by illuminating it, in the CloudCompare software, to improve the readability of the elements. These orthoimages and meshes were then integrated into 3ds Max to model the elements a little more finely. Because the architecture is fairly rectilinear and symmetrical, it has been possible to complete the parts not covered by the photogrammetry (cf. Figure 6).

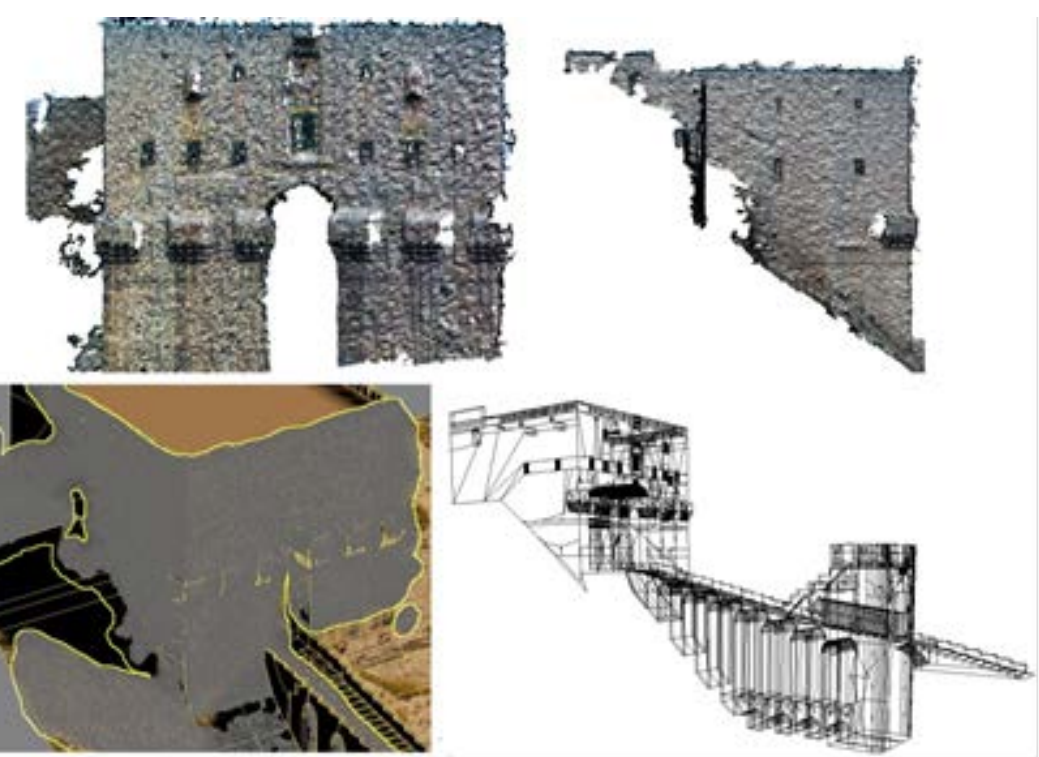

Fig. 6. Top: Illuminated front and side views which supported the $3 d$ modeling / bottom: mesh from photogrammetry on manual modeling and wireframe model redrawn (Polys: 704850 / Verts: 828 585)

\subsection{Texturing}

The next step is the enrichment of the 3D model from the initial geometric basis and thanks to a corpus of photos available on the internet, sometimes taken by professional photographers [7], and a 3D web virtual tour [27]. This corpus was constituted from selection of pictures obtained with a search on Google 
Web Search and the keywords "Citadel" and "Aleppo". The selection took into account both the resolution of the images and the coverage of the items of interest and gathered about 60 pictures (cf. Figure 7).

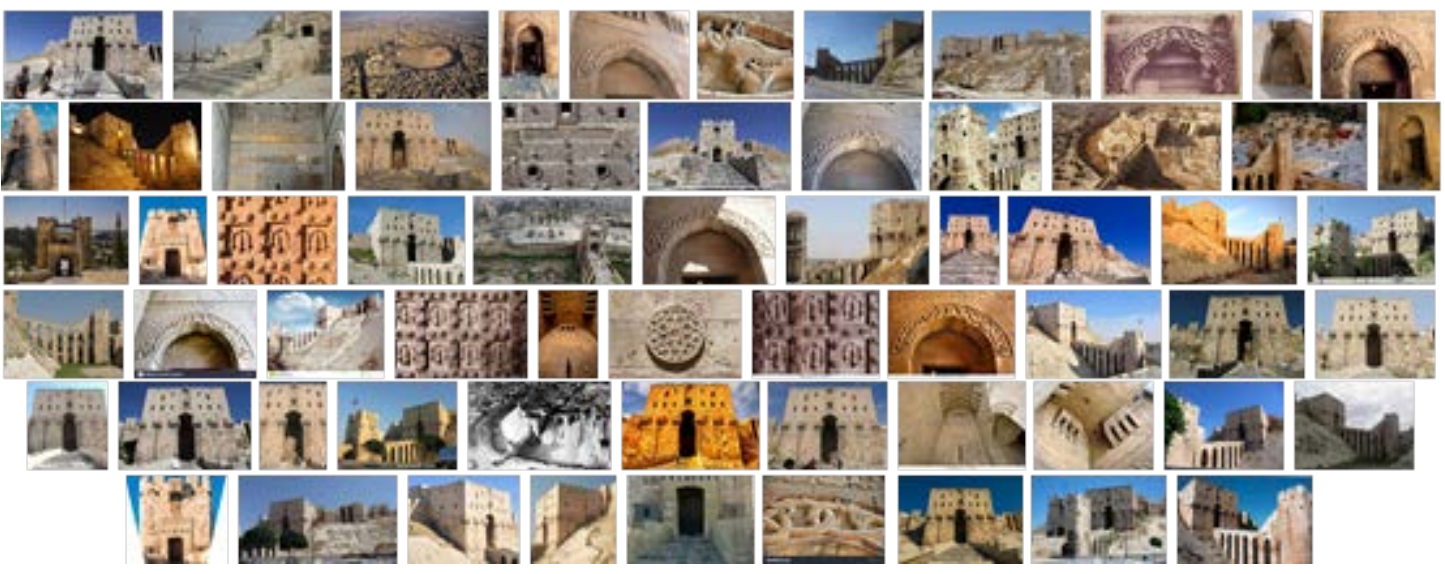

Fig. 7. Corpus of photos available from the internet intended to enrich the model

The enrichment of the 3D model is performed through an iterative process made up of four main steps (cf. Figure 8):

1. Orthophoto extraction from some photos of the corpus thanks to a "Perspective Crop Tool" (software photoshop CS6): it corrects trapezium or perspective distortions that occur, systematically in our corpus, when an object is photographed on an oblique plane and not on a normal plane. On some orthoimages with unwanted features, such as tourists in front of the lens, the use of Photoshop's "Clone Stamp Tool" is sometimes necessary to "remove" them. Color homogeneity, thanks to the Photoshop's "Match color" tool used with a reference texture, may also be relevant.

2. Manual 3d modeling of details from these orthophotos: when reading certain photos, the morphology of certain details becomes understandable. A finer sculpture of them, textured afterwards with uniform portions of these photos, allows to increase the realism. The diamond barred window, modeled after reading a photo with a high resolution on the area, illustrates this step.

3. Seamless texture extraction: it may happen that some parts to texture, such as the bottom of the outer gate, are not present in any photo of the corpus. We need thus to create a seamless and tileable texture. This technique, well known in computer graphics, consists of the use of the "Offset filter" photoshop. 4. Texture mapping in 3ds Max, especially with the UVW Map Modifier because the volumes are relatively simple.

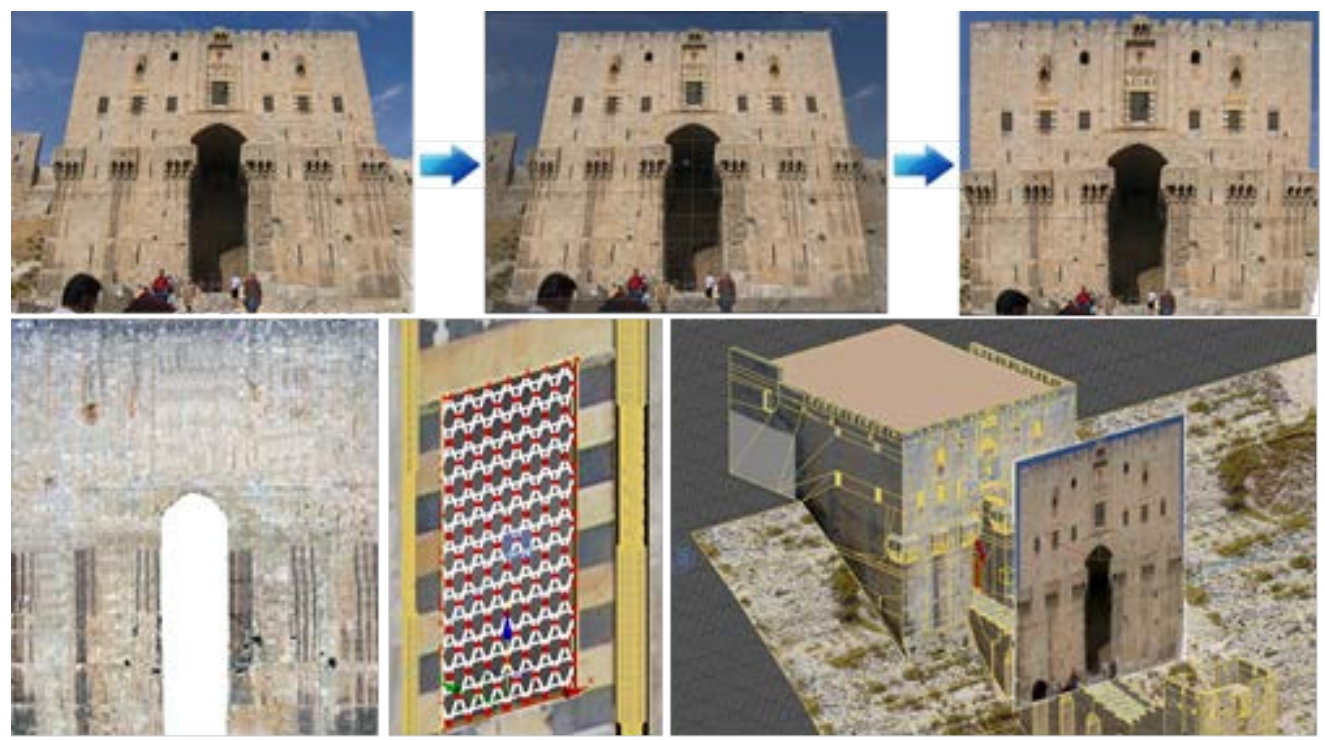

Fig. 8. Top: use of "Perspective Crop Tool" / Bottom: cleaned orthophoto with homogenized colors, diamond barred window modeled from a photo, front face of the gate mapped with the corresponding orthophoto (shown in 3d to illustrate the example) 


\section{Results}

The resulting 3D textured model is presented in Figure 9 and renderings are done with the CPU/GPU renderer V-Ray. There are still some uncovered lateral areas, unreadable engraved wall writings, and some details are reconstructed naively, but the essential items, allowing to visually characterize the fortified entrance as a whole, have been reconstituted. The 3D model was first used to produce some renderings intended to obtain first reviews from archaeologists and architecture specialists, photos and complementary documents allowing correcting and filling the gaps.
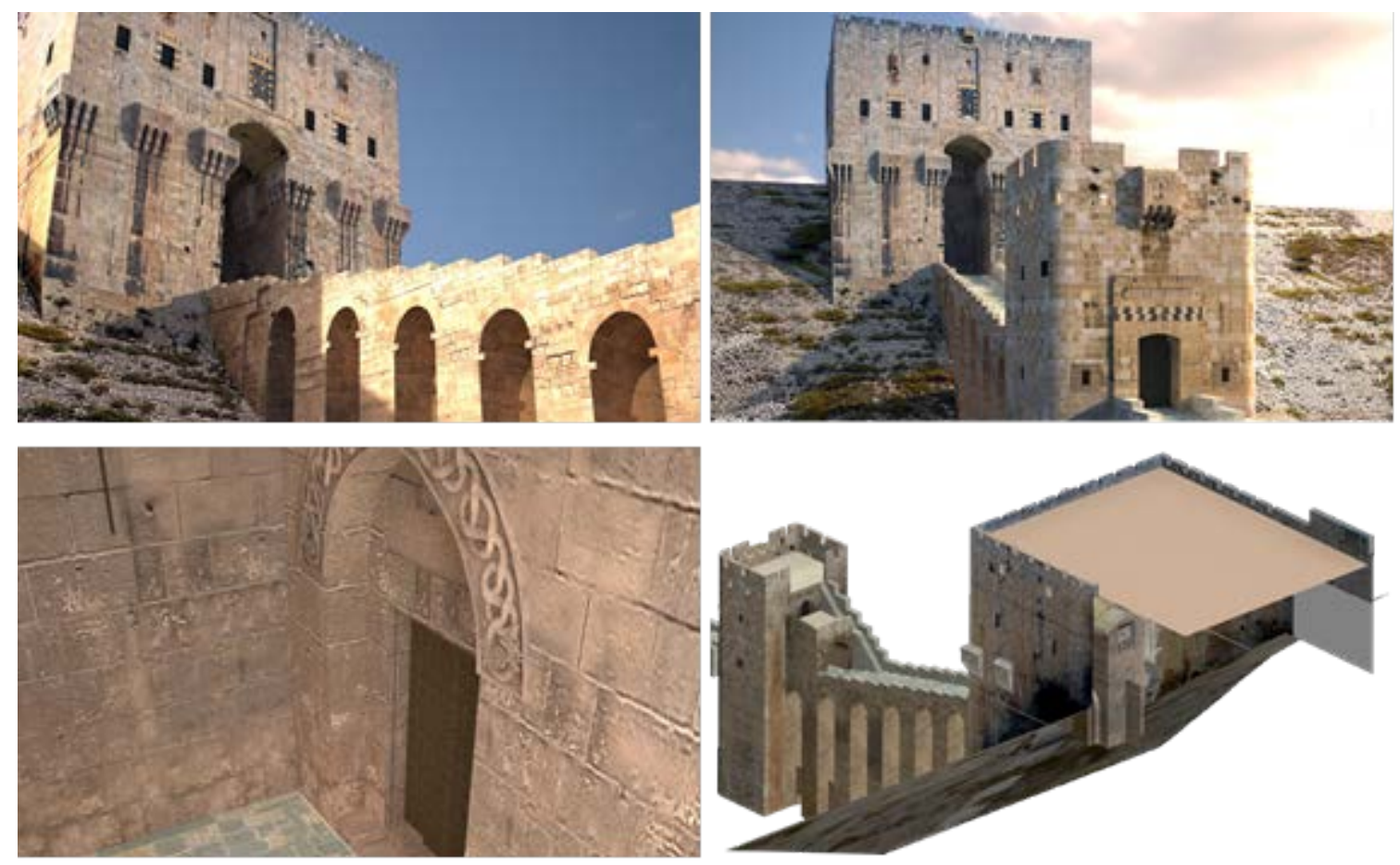

Fig. 9. Rendering of the resulting 3D textured model: the inner gate overlooking the arched bridge (top), the outer gate in the foreground (center), the entrance with reliefs depicting dragons (bottom left) and a side view illustrating the need for a better resolution photo of the right wall and the lack of details on the roof (bottom right)

In order to test its geometric relevance, a comparison between our model and the one that is downloadable from sketchfab [16] was first performed. However, the validity of it is not assured and this overlay shows many differences (cf. Figure 10). It should be interesting to compare the model we produced with more reliable models such as the one in [10]. Beyond the comparison of the resulting models, it should also be interesting to mix our approach with the previous works fully based on automatic reconstruction from photogrammetry. We believe that our approach can be complementary of automated methods in order to improve the resulting meshes, under the condition of a careful control of the coherency of the images added during the texturing phase in order to avoid inconsistent representations. 


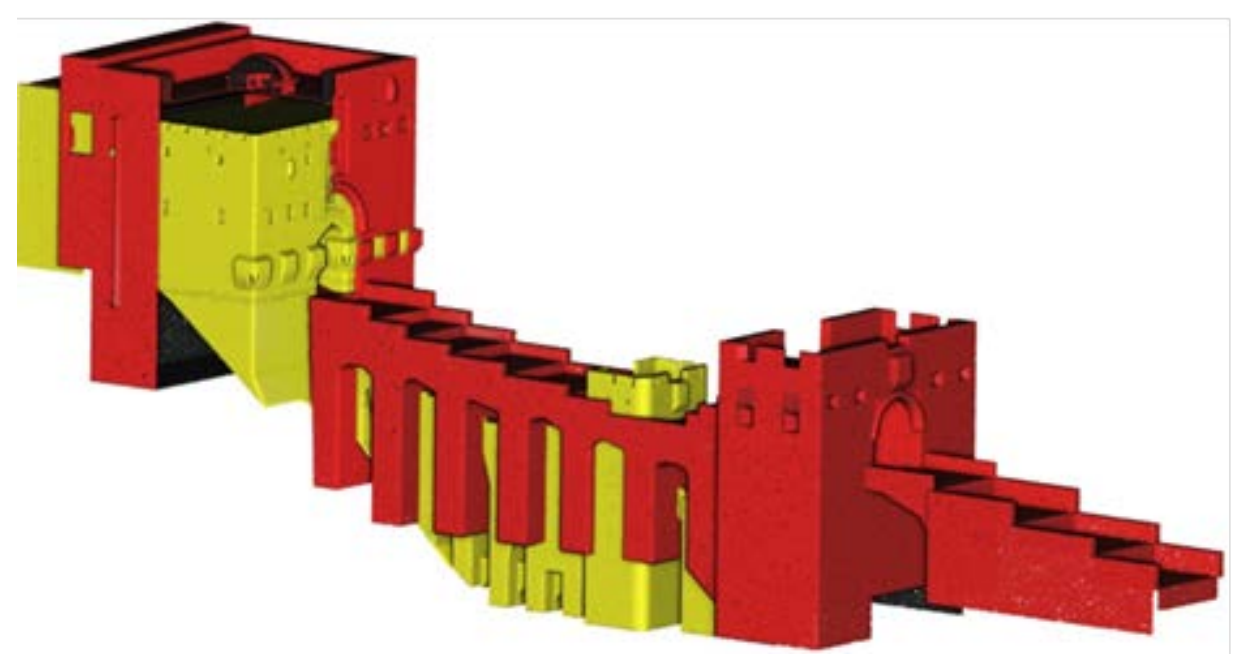

Fig. 10. A cutaway model of the one that is downloadable from sketchfab [16] (in red) over our model (in yellow) with CloudCompare software

The second approach consisted of inlays of our model on various existing photos. To do this, we used the tool "Perspective Match" de 3ds Max which uses a background image to orient a camera so that its position and field-of-view match the perspective of the image (cf. Figure 11). This method makes it possible to reveal several differences, such as the height of the bridge, which will involve corrections. The goal here is to highlight the value of an iterative process that is self-monitoring. 


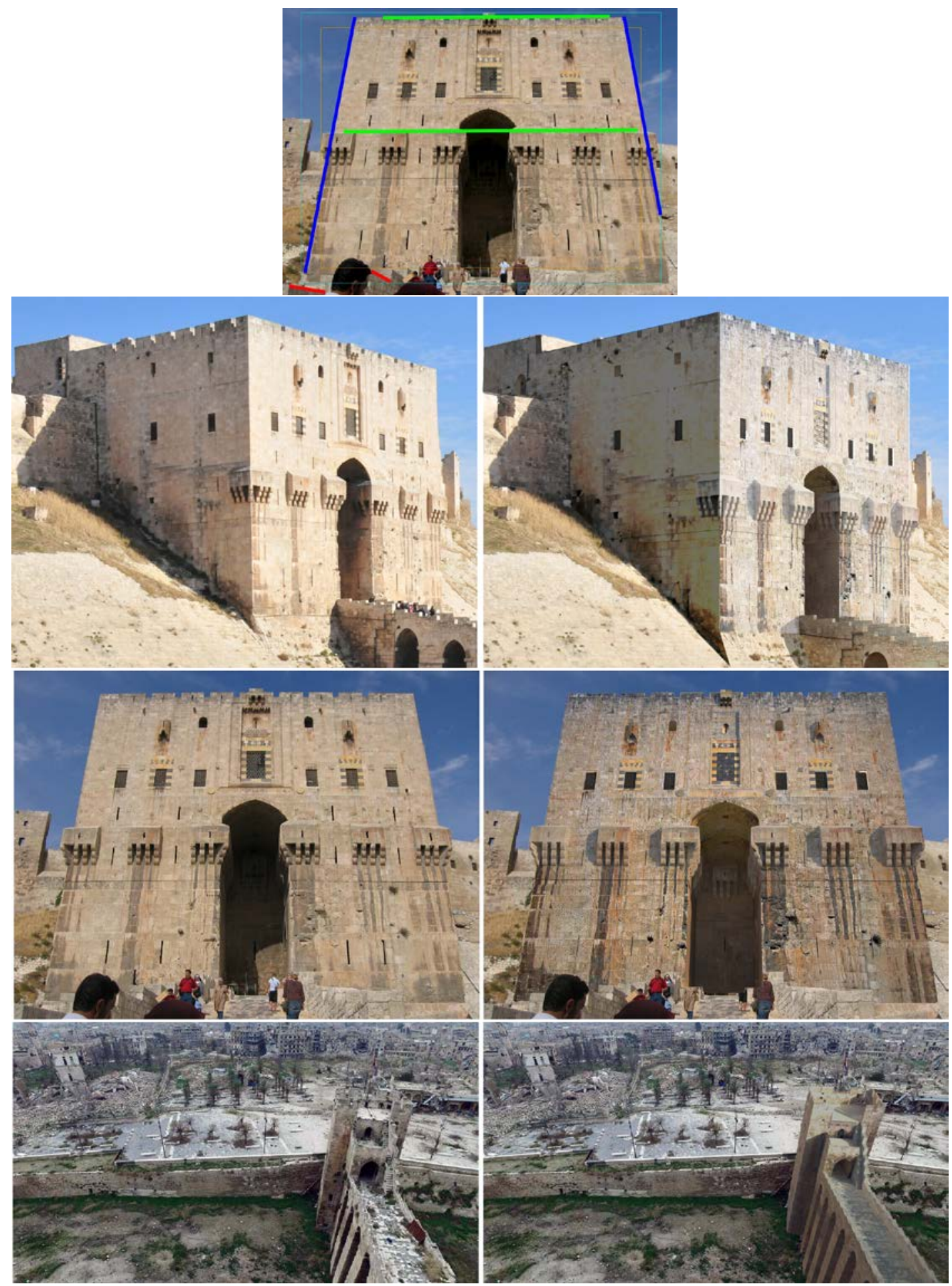

Fig. 11. Top : view of the "Perspective Match" tool in 3DS Max / Left : original images / Right : Inlaid views of our $3 \mathrm{D}$ model

This 3D representation of the Citadel of Aleppo was made possible thanks to:

1. Taking at least 3 sightseeing photos by making a quarter turn around the building (it is likely that the photographer was not aware that it offered the possibility of photogrammetry)

2. Many architectural symmetries and relatively simple volumes to deduce a large number of elements not covered by the photogrammetry

3. An absence of deadline constraints, concerning the 3D production, making possible the iterative process of a relatively completed modeling, carried out by a single person by intermittence. 
It is unlikely that conditions 1 and 2 will be fulfilled for possible process applications on other archaeological sites. However, we believe that, if the evolutions of the photogrammetry techniques will make it possible to obtain similar results, even smaller or too heterogeneous corpuses of sightseeing photos, it will be quite possible to apply the process.

\section{Perspectives}

In the immediate future, we want to develop a collaborative process to improve the model, based on an exchange with experts of the domain.

To do this first of all, we want to study the possibilities of textured 3d printing that are currently emerging [25] [30]. The objective would be to observe, with a 3D printed citadel at a given scale, the differences between finely sculpted or textured details.

At the same time, we are considering to deploy the 3D model at scale 1 within the Immersia platform [11] or in a virtual reality headset, to propose experiments around the validation of the reconstitution by experts. We believe that this kind of model can be integrated into a collaborative work application, where users can add annotations, or even 3D sketches to complete certain parts.

As for the possibilities of mediation, these are obviously numerous, but they are not the heart of our objectives. We will however try to feed interactive websites dedicated to 3D display of heritage under threats. With regard to other Syrian sites, there is still a lot of things to develop. For example, it would be interesting to test the latest reconstruction techniques from a single image [17] on sculted elements present in a single photo. We are also currently interested in the destroyed funeral towers of Palmyra.

\section{References}

[1] Aleppo on the road to damascus, 2011. http://www.bigjourney.ru/little-journeys/turkey-and-syria- april2011/aleppo-po-puti-v-damask.

[2] AhmedKiing. Citadel of aleppo (adventure), 2012. https://www.planetminecraft.com/project/citadel- ofaleppo-adventure/.

[3] Alafandi, R., and Rahim, A. A. Architectural heritage of aleppo: past, present and future. In 3th International Conference on Universal Design in the Built Environment 2013 (ICUDBE2013), Kulliyyah of Architecture and Environmental Design, Putrajaya International Convention Centre (PICC) Malaysia, 11th-12th November 2013 (2013), International Islamic University Malaysia, pp. 1-17.

[4] Andrés, A. N., Pozuelo, F. B., Marimón, J. R., and de Mesa Gisbert, A. Generation of virtual models of cultural heritage. Journal of Cultural Heritage 13, 1 (2012), 103-106.

[5] Barreau, J.-B., Gaugne, R., Bernard, Y., Le Cloirec, G., and Gouranton, V. The West Digital Conservatory of Archaelogical Heritage Project. In DH (France, 2013), pp. 1-8.

[6] Brande-Lavridsen, O., and Juhl, J. A photogrammetric survey of a drilling platform. International Archives of Photogrammetry and Remote Sensing 27 (1984), 111-115.

[7] Demeter, D. Aleppo - aleppo citadel, 2015. http://www.syriaphotoguide.com/home/aleppo-aleppo- citadel.

[8] Dog, N. The art of the Uncharted Trilogy. Dark Horse Comics, 2015.

[9] Fangi, G. Documentation of some cultural heritage emergencies in syria in august 2010 by spherical photrammetry. ISPRS Annals of the Photogrammetry, Remote Sensing and Spatial Information Sciences 2, 5 (2015), 401.

[10] Fangi, G., Piermattei, L., and Wahbeh, W. Spherical photogrammetry as rescue documentation for the reconstruction of some unesco sites in syria. International Journal of Heritage in the Digital Era 2, 3 (2013), 335-341.

[11] Gaugne, R., Gouranton, V., Dumont, G., Chauffaut, A., and Arnaldi, B. Immersia, an open immersive infrastructure: doing archaeology in virtual reality. Archeologia e Calcolatori, supplemento 5 (2014), 1-10.

[12] Grousset, R. The empire of the steppes: a history of Central Asia. Rutgers University Press, 1970.

[13] Han, I., and Kang, H. Three-dimensional crush scanning methods for reconstruction of vehicle collision accidents. International journal of automotive technology 17, 1 (2016), 91-98. 
[14] Hartmann, W., Havlena, M., and Schindler, K. Towards complete, geo-referenced 3d models from crowdsourced amateur images. ISPRS Annals of Photogrammetry, Remote Sensing \& Spatial Information Sciences 3, 3 (2016).

[15] Hashemi, N., Nourollahichatabi, S., et al. Image-based models using crowdsourcing strategies. DIGITCULT 1, 3 (2016), 65-79.

$\begin{array}{lllll}\text { [16] Issa, } & \text { H. } & \text { Sketchfab } & \text { aleppo } & \text { castle, }\end{array}$ https://sketchfab.com/models/6f129c1d9eee4c4b98dc4c167c202e90.

[17] Jackson, A. S., Bulat, A., Argyriou, V., and Tzimiropoulos, G. Large pose 3d face reconstruction from a single image via direct volumetric cnn regression. In Computer Vision (ICCV), 2017 IEEE International Conference on (2017), IEEE, pp. 1031-1039.

[18] Kitamoto, A., Andaroodi, E., Matini, M., and Ono, K. Post-disaster reconstruction of cultural heritage: citadel of bam, iran. In Proceeding of IPSJ SIG computers and the humanities symposium, Kyoto (2011), pp. 11-18.

[19] Knost, S. Living with disaster: Aleppo and the earthquake of 1822. In Historical Disaster Experiences. Springer, 2017, pp. 295-305.

[20] Lafi, N. Building and Destroying Authenticity in Aleppo: Heritage between Conservation, Transformation, Destruction, and Re-Invention. In Gebaute Geschichte. Historische Authentizität im Stadtraum, A. S. Christoph Bernhardt, Martin Sabrow, Ed. Wallstein, July 2017, pp. 206-228.

[21] Lopez-Romero, E., and Daire, M.-Y. The icare project: Insights into the formation and consolidation of archaeology in western france (ca. 1850-1990). Bulletin of the History of Archaeology 23, 1 (2013).

[22] Luhmann, T., Robson, S., Kyle, S., and Harley, I. Close range photogrammetry. Wiley, 2007.

[23] Mayda, M. Forensic photogrammetry: A case study, 2017. https://info.photomodeler.com/blog/forensicphotogrammetry-case-study/.

[24] Somogyi, A., Barsi, A., Molnar, B., and Lovas, T. Crowdsourcing based 3d modeling. International Archives of Photogrammetry, Remote Sensing \& Spatial Information Sciences 41 (2016), B5.

[25] Song, H., and Lefebvre, S. Colored fused filament fabrication. arXiv preprint arXiv:1709.09689 (2017).

[26] Spring, D. Des images contre le néant, 2016. http://wp.unil.ch/allezsavoir/des-images-contre-le-neant/.

[27] Turlar, S. The citadel of aleppo - 3d virtual tour, 2009. http://www.3dmekanlar.com/en/the-citadel- ofaleppo.html.

[28] Vincent, M. L., Gutierrez, M. F., Coughenour, C., Manuel, V., Bendicho, L.-M., Remondino, F., and Fritsch, D. Crowd-sourcing the 3d digital reconstructions of lost cultural heritage. In Digital Heritage, 2015 (2015), vol. 1, IEEE, pp. 171-172.

[29] Wahbeh, W., Nebiker, S., and Fangi, G. Combining public domain and professional panoramic imagery for the accurate and dense 3d reconstruction of the destroyed bel temple in palmyra. ISPRS Annals of Photogrammetry, Remote Sensing \& Spatial Information Sciences 3, 5 (2016).

[30] Willis, S. The maker revolution. Computer 51, 3 (2018), 62-65.

[31] Yilmaz, H. M., Yakar, M., Gulec, S. A., and Dulgerler, O. N. Importance of digital close-range photogrammetry in documentation of cultural heritage. Journal of Cultural Heritage 8, 4 (2007), 428-433. 